\title{
How Do the Mass Media Report the Controversial Scientific Issues? -from Two Classics on Science Communication in the 20th Century
}

\author{
Wanhong Pang \\ Xi'an International University, Xi'an Shaanxi, 710127, China
}

Keywords: Science communication, “The Public Understanding of Science”, "Science and Society", scientific community

\begin{abstract}
The mass media fall in between the science and the public, which bear the important responsibility for science communication. In the modern society, more and more scientific issues and social issues are intertwined. There are two classics on the Western science communication in the last century having the important practical significance for science communication. On the controversial scientific issues, we shall report the risk and uncertainty of science carefully and respect the "scientific consensus" in the controversial issues. The media and the "scientific community" shall respect each other and establish a relation for communication and cooperation; the government shall strengthen the guidance for science communication and create conditions for the communication between the media and the scientific community; the mass media shall establish strict criterions and standards for the science reporting.
\end{abstract}

\section{Introduction}

In the modern society where we live in, there are more and more complicated scientific and social issues intertwined together, such as the high-profile issue of genetically modified food in recent years, the PX factory emerging in various regions, the Not-In-My-Back-Yard on the site selection for waste incineration and the safety of electromagnetic wave. Undoubtedly, all of them should be reported with the close cooperation between the scientific community and the media. However, the communication and cooperation between the media and the scientific community were unsatisfactory, and even there were some conflicts and misunderstandings between them, so that the intervention of the media didn't extinguish the conflicts and misunderstandings but increased more. As more and more scientific issues overflow to become the social issues, it is particularly urgent for the mass media to duly handle the controversial scientific issues and promote the communication and cooperation between the media and the scientific community. After 2000, as China attached importance to the science communication, some domestic scholars in the fields of the philosophy of science and the history of science translated and introduced a series of literatures on scientific communication, especially the Public Understanding of Science and the Science and Society were of great significance for the research and development of China's science communication.

\section{The two references on science communication born in the late 20th century}

In the late 20th century, with the development of genetic inheritance, medical transplant and nuclear power technology, especially the application of transgenic technology and other technologies in the western developed countries, the science attracted more and more attention from the ordinary people, resulting in many reports on the security concerns and ethical arguments of new technology. Therefore, it was urgent for the western developed countries to let the public understand the relationship between the science and the society and alleviate it. In this background, two important literatures which could be called as the milestones of science communication were published, which were the Public Understanding of Science published by Royal Society in 1985 and the Science and Society published by the Special Committee on Science and Technology of the House of Lords of 


\subsection{The background of the two references on science communication born in the 20th century}

The Public Understanding of Science was a report on the science communication published by the Royal Society in 1985, which is a landmark literature in the history of science popularization and science communication, and has the important reference value for the theory and practice of scientific communication in all countries. In April, 1984, the Royal Society Council established a special group chaired by Dr. Bodmer (Sir Walter F. Bodmer), a famous geneticist, including the experts from all fields of the Royal Society. The tasks of this special group were to assess the basic state of the public on the understanding of science and the importance of the public understanding of science to the development of the state, investigate the difficulties in the science communication, and put forward some suggestions for the improvement of science communication. The group published the Public Understanding of Science in 1985, which was regarded as a "classic literature for the public understanding of science in Britain and even in the world". There were some suggestions in the report. Some were for the "scientific community" including the Royal Society itself, and some were for the mass media, educational field, government, etc. After the publication, the report played a positive role in promoting the theory and practice of scientific communication.

The Public Understanding of Science published in 1985 gave a legal status to the scientific communication, pointed out the significance of media to the public understanding of science, and put forward some suggestions for the "scientific community" on how to make contact with the mass media and how to establish a good scientific public image. In the Science and Society published in 2000, there were more suggestions on the constructive cooperation between the scientists and the media and many constructive suggestions for the responsibility of the "scientific community" in the science communication and the methods for the scientific community to communicate with the media, so it still has a very important value until to now.

\subsection{The insufficient communication between the mass media and the "scientific community"}

The two reports were given full attention to the communication and cooperation between the science and the media. In the report published by the Royal Society in 1985, it was pointed out that it was very important for the scientists to keep a good cooperation with the journalists so that they could report the science news appropriately. However, the reality was that the scientists didn't understand the media enough or trust them, and they often were unwilling to make contact with the journalists and lacked the skills to communicate with the media. In the investigation report published by the Special Committee on Science and Technology of the House of Lords of Britain in 2000, the scientists' opinions didn't change seemingly, and "many scientists believed that the media would handle the science badly".

The relationship between the media and the scientific community was not optimistic, which was embodied in two aspects: on the one hand, the "scientific community" didn't trust or understand the mass media, and was unfamiliar with the propagation law and operation mode of mass media; on the other hand, the mass media didn't understand the "scientific community" enough, and knew the essence and law of science and technology insufficiently, so that the "scientific community" and the mass media became two independent groups.

When the two groups which stuck to their respective professional intersected with each other, there was a difference between the professional of media and the professional of science, and the scientists' discourse system was different from that of the media, resulting in a situation that they couldn't understand each other at all. In an example taken by Tim Radford, a science editor of The Guardian: a professor held a press conference on the research of mantle and centrosphere, on which he mentioned a 6-inch naval gun in his office, but the professor answered all the questions about the gun in the remaining time of the press conference. The intention of the professor was to tell the public about the science of the earth's core, but what the journalists wanted was a completely different report. The reason why this situation appeared was because the concerns of the journalists and the scientists were different, and their starting points were their own "professions". 
Therefore, in order to make the media favor the scientific information, scientists need to provide more information that can attract the audiences' attention in their professional fields; the news media shall reflect on themselves that whether they reported the news with pure news value and whether they listen to more suggestions from the scientists in the scientific reports.

\section{How the mass media report the controversial scientific issues}

The mass media are between the science and the public, which bear the responsibility for interpreting the information from the "scientific community" and spreading it to the public. If the media are unable to handle the scientific issues carefully, they may mislead the audience and cause some severe consequences, because many scientific issues are not only limited to the field of science, but also are intertwined with some social issues. The two literatures on the science communication born in the 20th century contained some prospective understanding of the means for the media to handle the scientific issues, especially on the conveying of risk and uncertainty of science, the "scientific consensus" and minority opinions. Today, they are still worth being thought by the media.

\subsection{Report the risk and uncertainty of science carefully}

How the media convey the risk and uncertainty of science to the society has been one of numerous controversial scientific issues in recent years. When scientists express the new progress of science and the application of new technologies, they are unable to give definitive conclusions, but the media often require the foolproof guarantee. For example, on the promotion of any kind of vaccine, scientists are unable to give an absolute commitment for security, because the absolute "zero risk" is nonexistent.

Under the premise that the determinacy is unable to be guaranteed, the media are actually caught in a dilemma on the reporting of risk and uncertainty: based on the public interest, the mass media need to tell the audience the possible risk, but the negative effect caused by the risk report will result in some chaos or panics, which are very evident in the medical technology and environmental field that are related to the vital interests of the public. In 1974, British media reported that some children had some severe nervous system reactions after the vaccination of diphtheria pertussis tetanus (DPT). Subsequently, with the continuous and wide reporting by media and TV, the public lost the confidence in the vaccine safety, resulting in the interruption of vaccination: the vaccination rate decreased to $31 \%$ from $81 \%$. Almost in the same period, some Japanese media reported the untoward effect of DPT vaccine, resulting in a scene as same as that in Britain: the vaccination rate of DPT in 1974 was $80 \%$, but it was only $10 \%$ in 1976 ! The bad consequence of the decline of vaccination rate in Britain emerged gradually after 10 years: the measles occurred in some regions in succession. In 2012, there were 2016 cases of measles confirmed in England and Welsh, which had been the highest in the past 20 years since 1994.

In recent years, some Chinese media have reported the severe side effect of the vaccination for children, which have caused the parents' worries, so that they think children shall not be vaccinated if possible. A survey showed that $71.4 \%$ of the people who were unwilling to be vaccinated were worried about the side effects. A key factor for this situation is the misleading by media.

\subsection{Respect the "scientific consensus" in the controversial issues}

In the report of controversial scientific issues, is the media biased or equal to the "scientific consensus" and the opinions of minority scientists? For this question, there were some thought-provoking questions put forward in the literatures.

First of all, it is the balance principle of news reports and the controversy of scientific issues. In the controversial reports, undoubtedly, it meets the balance principle of news report and is fair to equally treat the two parties of disputes. Charles L. Overby thought the fairness of news was composed of five basic elements, which were accuracy, balance, integrity, unbiasedness and ethics. However, in the controversial scientific issues, the balance principle of report seems not to be really objective and impartial. In the Science and Society, it is pointed out that this practice should be criticized: the media 
shall treat the "scientific consensus" and minorities equally without discrimination, because sometimes it can help to balance the relationship between them and sometimes the confrontation itself is a good news material. This phenomenon has been particularly evident in the report of domestic genetically modified food in recent years.

Secondly, in the report of controversial scientific issues, how to report the "scientific consensus" and the minority opinions? From the principles showed in the two important literatures on science communication, the mass media shall respect the scientific consensus and shall not exaggerate the minority opinions. The science field shall encourage people to query, but not all questions are worth being presented.

\section{How do the mass media make contact with the "scientific community"?}

On the scientific issues, the scientific community and the media shall go hand in hand to improve the relationship between them. In this way, what shall the scientific community do? What shall the media do?

First of all, the media and the "scientific community" shall respect each other and establish a benign cooperative relationship. The mass media is not opposed to the scientific community. The "scientific community" and the media shall respect each other, the "scientific community" shall not despise the mass media with its scientific expertise; when the mass media are involved in the more and more scientific issues, they shall be more cautious to avoid misleading the public. "We recommend ... to organize a press seminar for the journalists, so that everyone can understand the foreseeable or unforeseeable scientific progress in the current social hot issues.”

Secondly, the government shall strengthen the guidance on science communication and create conditions for the communication between the media and the scientific community. The British government established a Science Media Center in 2002, which is an independent institution and cooperates with the Royal Society. Its main purpose is to guide the media to report the controversial scientific issues fairly and reasonably, so as to improve the public trust in science. The main service objects of the center are the non-professional journalists in the mass media and the media without journalists who are specialized in the reporting of scientific issues. The center is like a media editorial office, which responds to the current events on science in time and collects various scientific views widely. In addition, the Science Media Center provides the lists of experts for the media, who are willing to receive interviews or make professional responses on the current events related to scientific problems. Moreover, the center provides the training for the scientific community to improve their ways to communicate with the media.

\section{Acknowledgements}

This research was financially supported by a project of the National Social Science Fund of China: research on the community conflict and communication in cities in the background of social transformation (Grant NO. 13BXW048), and a project of the Social Science Fund of Xi'an: research on the narrative strategy of the foreign publicity of Xi'an in the context of new media (Grant NO. 17X16).

\section{References}

[1] Jiang Xiaoyuan, Liu Bing, What Is the "Public Understanding of Science", the Digest of Science and Technology, 2005 (4): 8-9.

[2] the Royal Society, the Public Understanding of Science, translated by Tang Yingying, Beijing: Beijing Institute of Technology Press, 2004: 43.

[3] the Special Committee on Science and Technology of the House of Lords, the Science and Society, translated by Zhang Butian and Zhang Donglin, Beijing: Beijing Institute of Technology Press, 2004: 97. 
[4] Zhan Zhengmao, Jin Yi, Chen Xiaoqing, Annual Report on Science Communication of China (2010-2011), Beijing: Social Sciences Academic Press, 2011: 12-13.

[5] the Special Committee on Science and Technology of the House of Lords, the Science and Society, translated by Zhang Butian and Zhang Donglin, Beijing: Beijing Institute of Technology Press, 2004: 99.

[6] Gao Feng, Wang Xiaoxiao, the Vaccine Panic Is a World Problem, Global People, 2014 (1): 74-75.

[7] Liang Yulan, Qiu Juliang, the Communication System of British Scientific Culture and the Measures, Science News, 2007 (15): 5-7. 